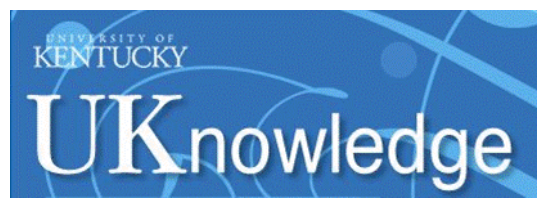

University of Kentucky

UKnowledge

Power and Energy Institute of Kentucky Faculty Publications

$1-27-2017$

\title{
Coreless Multidisc Axial Flux PM Machine with Carbon Nanotube Windings
}

\author{
Vandana Rallabandi \\ University of Kentucky, vandana.rallabandi@uky.edu \\ Narges Taran \\ University of Kentucky, narges.taran@uky.edu \\ Dan M. Ionel \\ University of Kentucky, dan.ionel@uky.edu \\ John F. Eastham \\ University of Bath, UK
}

Follow this and additional works at: https://uknowledge.uky.edu/peik_facpub

Part of the Power and Energy Commons

Right click to open a feedback form in a new tab to let us know how this document benefits you.

\section{Repository Citation}

Rallabandi, Vandana; Taran, Narges; Ionel, Dan M.; and Eastham, John F., "Coreless Multidisc Axial Flux PM Machine with Carbon Nanotube Windings" (2017). Power and Energy Institute of Kentucky Faculty Publications. 46.

https://uknowledge.uky.edu/peik_facpub/46

This Article is brought to you for free and open access by the Power and Energy Institute of Kentucky at UKnowledge. It has been accepted for inclusion in Power and Energy Institute of Kentucky Faculty Publications by an authorized administrator of UKnowledge. For more information, please contact UKnowledge@lsv.uky.edu. 


\title{
Coreless Multidisc Axial Flux PM Machine with Carbon Nanotube Windings
}

\author{
Digital Object Identifier (DOI)
}

https://doi.org/10.1109/TMAG.2017.2660526

\section{Notes/Citation Information}

Published in IEEE Transactions on Magnetics, v. 53, issue: 6.

(C) 2017 IEEECopyright Notice. "Personal use of this material is permitted. Permission from IEEE must be obtained for all other uses, in any current or future media, including reprinting/republishingthis material for advertising or promotional purposes, creating new collective works, for resale or redistribution to servers or lists, or reuse of any copyrighted component of thiswork in other works."

The document available for download is the authors' manuscript version that is accepted for publication. The final published version is copyrighted by IEEE and available as: V. Rallabandi, N. Taran, D. M. Ionel and J. F. Eastham, "Coreless Multidisc Axial Flux PM Machine with Carbon Nanotube Windings," in IEEE Transactions on Magnetics, vol. 53, no. 6, pp. 1-4, June 2017. doi: 10.1109/TMAG.2017.2660526 


\title{
Coreless Multidisc Axial Flux PM Machine with Carbon Nanotube Windings
}

\author{
Vandana Rallabandi ${ }^{1}$, Narges $\operatorname{Taran}^{1}$, Dan M. Ionel ${ }^{1}$, Fellow, IEEE, and John F. Eastham ${ }^{2}$ \\ ${ }^{1}$ University of Kentucky, Department of Electrical and Computer Engineering, Lexington, KY 40506, USA \\ ${ }^{2}$ University of Bath, Claverton Down, Bath, BA2 7AY, UK
}

\begin{abstract}
Coreless axial flux permanent magnet machines are attracting increasing attention due to their compact structure and high torque density. The torque to weight ratio can be further enhanced by the use of alternate conductor materials such as carbon nanotube (CNT), or aluminium windings in place of the copper material coils. This paper proposes a coreless axial flux permanent magnet synchronous motor with CNT windings. Analytical equations are developed to allow a systematic comparison of machine designs with different conductor materials. The performance of machine designs with different coil materials, namely copper, aluminum, CNT, are evaluated and compared. The calculations are also backed by 3D finite element analysis.
\end{abstract}

Index Terms-axial flux machine, coreless motor, carbon nanotube conductors.

\section{INTRODUCTION}

Coreless axial flux permanent magnet (AFPM) machines have the advantages of high torque density and compact structure. The coreless AFPM machine topology considered in this paper includes multiple stacks of rotors with surface mounted permanent magnets, and stators (Fig. 1). This machine topology offers several benefits, i.e., high power factor, no stator iron loss. In this machine, the stator consists mostly of copper coils which constitute a significant proportion of the total mass of the machine. Copper coils also have the drawback of eddy current losses in high speed applications. Non-conventional conductors such as carbon nanotubes (CNT) can overcome some of the problems associated with copper. However, being more recent technology, extensive studies on the applicability of this material to electrical machinery are missing. This paper attempts to bridge this gap by studying the benefits of replacing the copper coils in a coreless AFPM machine with CNT windings.

Carbon nanotubes (CNT) exhibit excellent electrical, thermal, and mechanical properties with low mass density. Individual CNTs have very high conductivities (up to $100 \times$ $10^{6} \mathrm{~S} / \mathrm{m}$ ) along the axial direction. However, conductivity substantially decreases when individual CNTs are assembled to form macroscopic conductors, because of the isotropic conductivity of CNTs. The fibers produced today have a wide range of conductivities due to limited control over the alignment [1]. In addition, CNTs also have other significant properties, such as lack of skin effect and low temperature

Manuscript received November 20, 2016.

The authors are with the SPARK Laboratory, Department of Electrical and Computer Engineering, University of Kentucky, Lexington, KY 40506, USA. Vandana Rallabandi (email: vandana.rallabandi@uky.edu), Narges Taran (email: narges.taran@uky.edu), and Dan M. Ionel (email: dan.ionel@uky.edu). John F. Eastham is with University of Bath, Claverton Down, Bath, BA2 7AY, UK (email: jfeastham@aol.com). coefficient of resistance, that make them specially attractive options for utilization in electrical machines [1], [2].

Previous designs employing CNT wires for a low voltage high speed radial flux permanent magnet synchronous machine and of a high frequency transformer, previously reported by other authors in [3] and [4] respectively, reported low efficiencies as the special properties of CNT conductors were not entirely leveraged. The present paper brings further contributions to the subject matter by proposing the use of CNT based conductors in a coreless multidisc AFPM machine. In this machine, a reported problem is the high AC losses in the windings which are exposed to the fundamental air gap flux, unlike the slot leakage flux as in conventional machines, necessitating special winding technologies such as Litz wire, or copper conductors with multiple strands connected in parallel [5], [6]. Considering this, the use of CNT is expected to have a two-fold benefit, due to (a) The significantly lower mass density of CNT as compared to copper $\left(\frac{1}{6}^{\text {th }}\right)$ and (b) The lack of skin effect in CNT conductors. Both of these factors would lead to a machine with power density comparable to copper in certain cases.

This paper also reports a systematic framework for comparison of coreless AFPM machine designs with different conductor materials-copper, CNT, and aluminum. Since the properties of CNT wires reported in literature vary over a range, calculations in this study are performed for an average value of the reported conductivities, i.e., $6 \times 10^{6} \mathrm{~S} / \mathrm{m}$. Calculations are performed based on analytical equations and 3D FEA.

\section{Properties of DifFEREnt Conductor Materials}

The conductor materials considered for coreless AFPM in this paper include copper, aluminum and CNT. The electrical conductivity, mass density, and temperature coefficient of resistance of these materials are listed in Table I. Copper has been the popular conductor for electrical machine winding for many years, mainly because of its high conductivity and stability over time. Copper, being a non-precious metal, is relatively cost-efficient compared to alternatives with higher conductivity such as silver. However, it is not the preferred option for cost-sensitive and mass-sensitive cases. Considerable skin effect and eddy current losses at higher speeds and frequency is another important problem concerning copper coils [5].

Replacing copper coils with aluminum coils partly solves the cost issue, however it reduces the conductivity. Aluminum has over two times the specific heat capacity of copper, which implies that electrical equipment wound with aluminum has

Authors' manuscript version. The final published version is copyrighted by IEEE and available as: V. Rallabandi, N. Taran, D. M. Ionel and J. F. Eastham, "Coreless Multidisc Axial Flux PM Machine with Carbon Nanotube Windings,” in IEEE Transactions on Magnetics, vol. 53, no. 6, pp. 1-4, June 2017. doi: 10.1109/TMAG.2017.2660526 @2017 IEEE Copyright Notice. "Personal use of this material is permitted. Permission from IEEE must be obtained for all other uses, in any current or future media, including reprinting/republishing this material for advertising or promotional purposes, creating new collective works, for resale or redistribution to servers or lists, or reuse of any copyrighted component of this work in other works." 




Fig. 1: The exploded view of coreless AFPM machine 3D model with 3 stator and 4 rotor discs. Each stator stack has 12 coils and each rotor disc contains 16 PM poles. Only the two rotor stacks on the sides have back iron and magnets are surface mounted.

a better overload withstanding capability as compared with copper. Aluminum also has an electrical conductivity by mass ratio which is twice that of copper, indicating that the choice of aluminum conductors is a good one in weight critical applications [7]. In high frequency applications with aluminum winding, skin effect is still a problem. Solutions such as utilizing litz wire are often considered for high frequency applications which adds even more financial burden due to their complex and expensive coating process.

CNT wires are over $80 \%$ lighter than copper and $40 \%$ lighter than aluminum. They have virtually no skin effect and their resistance almost does not increase significantly with temperature [1], [3]. Presently, the main drawback of the CNT wire is its low electrical conductivity which results in bulkier machine designs. In applications which are weight sensitive but have no constraint on volume, for instance solar powered aircrafts, the use of CNT materials can be justified.

\section{AFPM MACHINE STRUCTURE AND MAIN SIZING EQUATIONS}

The motor considered for this study is a multidisc coreless AFPM machine that includes 4 rotor discs and 3 stator discs with 16 poles on each rotor stack and 12 coils on each stator stack. The motor is inspired by a machine originally developed for a EU stratospheric unmanned aircraft propulsion project [8]. Figure 1 shows the exploded view of the 3D model used for three-dimensional finite element analysis (FEA). In order to increase the speed of 3D FEA only two pole pairs of the whole structure was meshed and analyzed. The quarter model of the machine with copper coils is shown in Fig. 2. The specifications and main dimensions of the motor are presented in Table II.

TABLE I: MATERIAL PRoperties FOR Windings.

\begin{tabular}{lccc}
\hline Material & $\begin{array}{c}\text { Conductivity } \\
{[\mathrm{MS} / \mathrm{m}]}\end{array}$ & $\begin{array}{c}\text { Density } \\
{\left[\mathrm{kg} / \mathrm{m}^{3}\right]}\end{array}$ & $\begin{array}{c}\text { Temperature coefficient } \\
\text { of resistance }[/ \mathrm{K}]\end{array}$ \\
\hline Copper & 58.0 & 8960 & 0.0038 \\
Aluminum & 35.0 & 2700 & 0.0043 \\
CNT & 6.0 & 1500 & 0.0015 \\
\hline
\end{tabular}

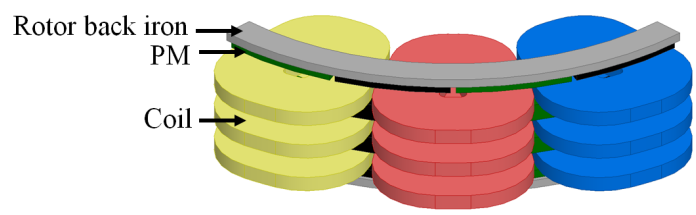

Fig. 2: Two pole pairs of the 3D model with surface mounted PMs.

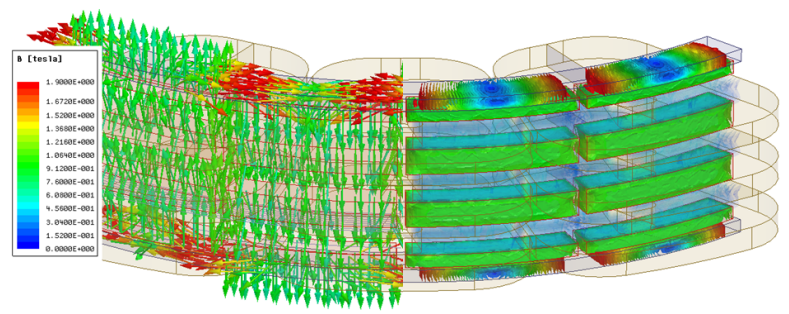

Fig. 3: Magnetic flux density magnitude and direction for two pole pairs of the 3D FEA model for the original coreless AFPM machine with copper coils.

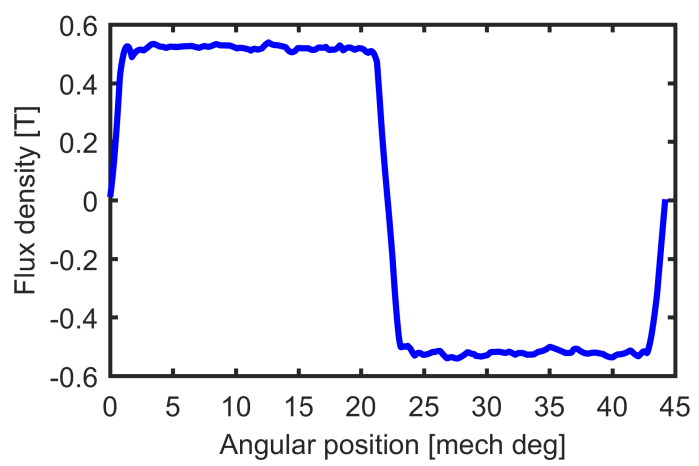

Fig. 4: Air-gap flux density at the mean radius obtained for the original coreless AFPM machine with copper coils.

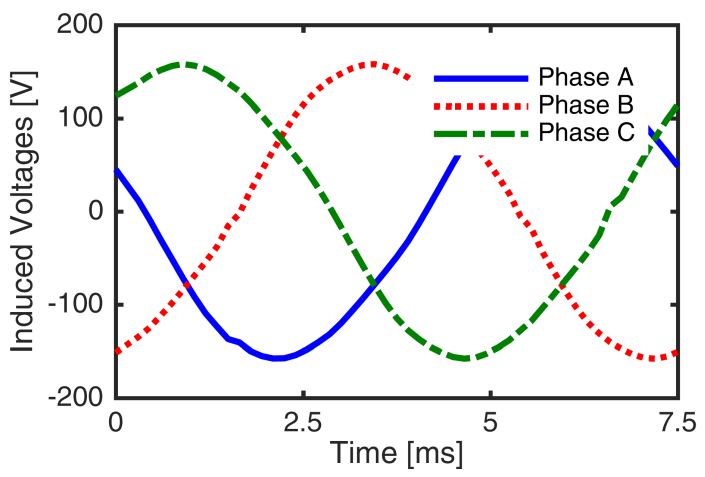

Fig. 5: Three-phase induced voltages for the original machine with copper coils.

TABLE II: SPECIFICATIONS OF THE CORELESS AFPM MACHINE, WITH COPPER COILS.

\begin{tabular}{lr}
\hline Rated power & $5 \mathrm{hp}$ \\
Rated speed & $3600 \mathrm{rpm}$ \\
Active outer diameter & $485 \mathrm{~mm}$ \\
Total axial length & $59 \mathrm{~mm}$ \\
Total active mass & $25.23 \mathrm{~kg}$ \\
\hline
\end{tabular}




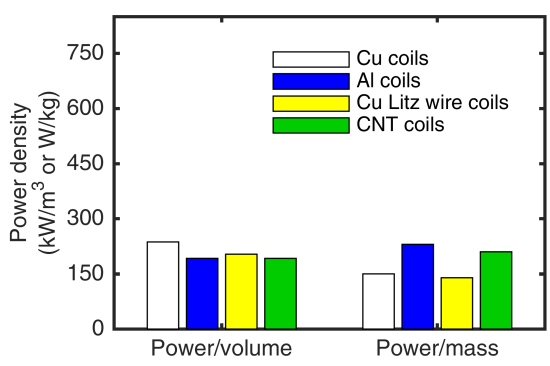

(a)

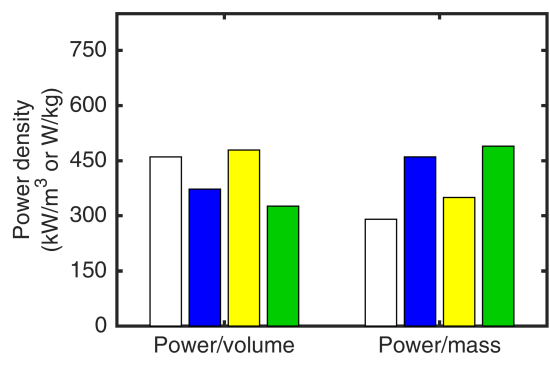

(b)

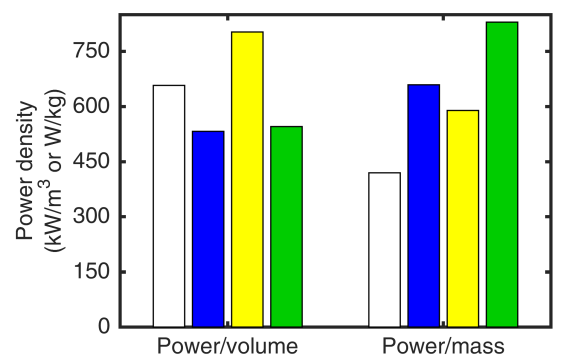

(c)

Fig. 6: Variation of power per unit volume and power per unit mass of the coreless AFPM machines with different materials for the coil. a) $3600 \mathrm{rpm}, \mathrm{b}) 7000 \mathrm{rpm}$, and c) $10000 \mathrm{rpm}$.

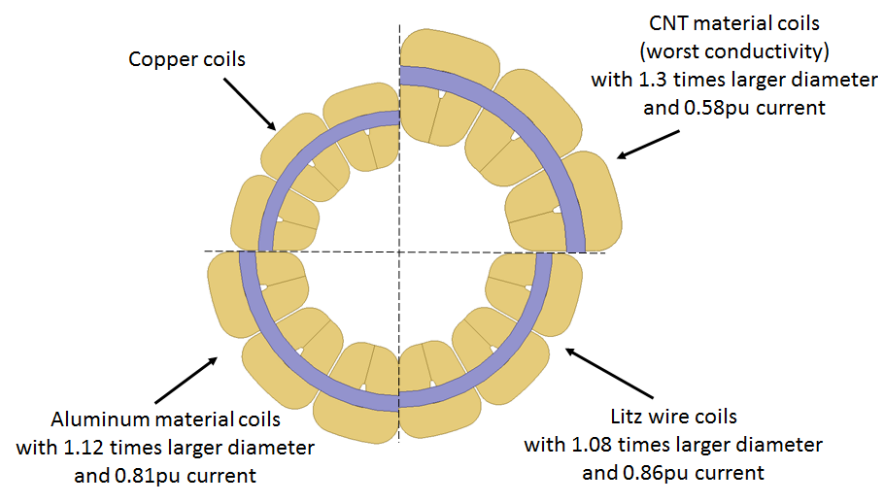

Fig. 7: Visual comparison of the diameter of the motor with copper, litz wire, aluminum, and CNT coils. The produced torque and loss per dissipation area in all three cases are kept the same.

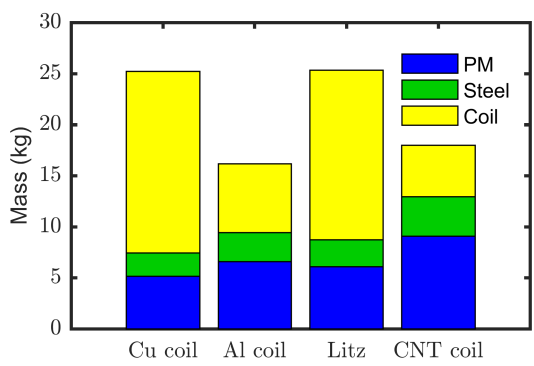

Fig. 8: The total weight and that of each component for the motor with copper coils, litz wire coils, aluminum coils, and CNT coils.

The generated electromagnetic torque, $T_{e m}$, for the AFPM machine can be calculated by

$$
T_{e m}=\frac{m p \pi^{2} s B_{m} C L \sqrt{\sigma} N D_{o}^{3}\left(1-\lambda^{2}\right)}{8 \sqrt{2}} .
$$

where $m$ is the number of phases; $p$, the number of poles, $s$, the slot fill factor; $B_{m}$, the maximum air-gap magnetic flux density; $L$, the axial length of the coil; $\sigma$, conductivity; $N$, the number of turns per phase; $D_{o}$, the outer diameter; $\lambda$, the ratio of inner to outer diameter of the rotor; and $C$ is a constant representing loss per unit conductor volume.

A relation between torque output and electrical conductivity of the winding of the motor may be derived in terms of the motor diameter and length as follows:

$$
T_{e m} \propto D_{o}^{3} \sqrt{\sigma} L .
$$

It can be seen that, keeping loss density constant, the produced electromagnetic torque is proportional to outer diameter, axial length, and the conductivity of the coils. If axial length is kept constant, in order to produce the same amount of rotational torque in two different designs, with two different conductor materials, the amount of diameter increase can be calculated by

$$
\frac{D_{o 2}}{D_{o 1}}=\sqrt[6]{\frac{\sigma_{1}}{\sigma_{2}}}
$$

If the outer diameter is kept constant, for the same torque production, the amount of increase in coil's axial length can be calculated by

$$
\frac{L_{2}}{L_{1}}=\sqrt{\frac{\sigma_{1}}{\sigma_{2}}} .
$$

Comparing equation (3) and (4), it is evident that adjusting diameter to offset the lower electrical conductivity results in a higher torque density compared to the case with adjusted axial length. As an example of the effect of increasing axial length versus increasing diameter, for the multidisc AFPM machine under study, using the properties of Table I, adjusting diameter (1.3 times more) to offset lower electrical conductivity in CNT coils makes the volume 1.73 times larger, while adjusting axial length (2.11 times more) results in a design with 1.85 times larger. For this reason, the focus of this study is to adjust the diameter of the designs, with different materials for coil, having the same loss per dissipation area at the rated torque.

\section{Performance eValuation and comparative STUDY}

Calculations are performed on the base AFPM machine with the rated values of $5 \mathrm{hp}$ and $3600 \mathrm{rpm}$. The 3D FEA was performed using ANSYS Maxwell 17.2 and the results coincide with nominal values. The flux density magnitude and vector, are plotted in Fig. 3. Figure 4 represents the air-gap flux density for one pole pair- 45 mechanical degrees. The induced three-phase voltages are plotted in Fig 5.

The copper coils are replaced with CNT coils, and aluminum coils. The electrical conductivity and mass density 
of each type of coil materials is displayed in Table I [1]. As the non-conventional materials are less conductive than copper, larger dimensions are needed to obtain the same torque, which is achieved by increasing the diameter. As a result of larger diameter the area available for the coils increases. Diameter is increased such that produced torque as well as loss per dissipation area for all studies are the same.

Figure 7 represents a visual comparison for the diameter of motors with different coil materials. The comparatively lower mass density of CNT wires leads to a lighter design although bulkier than the machine with copper coils. Figure 8 demonstrates the total weight and the weight of each component for motors with different winding materials. It is seen that for the copper based machine designs, the largest fraction of the mass is due to the coils, while the mass of coils for the CNT based machine is the lowest. Aluminum and CNT based machines also have lower mass.

To evaluate the effect of rated design speed on the performance of the machines with different materials, designs are done for rated speeds of: $3600 \mathrm{rpm}, 7000 \mathrm{rpm}$, and 10,000 rpm. Power per unit mass and power per unit volume are illustrated in Fig. 6. It can be seen that at $3600 \mathrm{rpm}$ CNT and $\mathrm{Al}$ based machines are lighter but larger than the other designs.

As the speed goes up, the power per unit mass of the CNT based machine improves by a greater proportion as compared to the copper based machine due to lack of skin effect in CNT wires. Due to AC losses in the copper conductors, the resistance at high frequencies in copper can be about 7 times the DC value [9], [10]. Furthermore, the effect of AC loss is higher in the coreless AFPM machine. Therefore, the comparison also includes Litz wire, which is used to reduce the AC loss in the coreless AFPM machine. In case of Litz wire, the AC losses are only considered to be double the DC losses at the highest speed of operation. Also, the use of Litz wire enforces a smaller slot fill factor, increasing the DC resistance.

At the design speeds of $7000 \mathrm{rpm}$ and $10,000 \mathrm{rpm}$ it is seen that the CNT based and Al based designs have significantly higher power per unit mass than both copper based designs. At $10,000 \mathrm{rpm}$, the CNT based machine has the best power per unit mass, although the design employing Litz wire offers the best power per unit volume. It is also observed that the design with Aluminium coils has a higher power per unit mass than the designs with copper coils irrespective of operating speeds. Further improvements can be achieved by employing compressed Aluminum technology which would allow very high slot filling factors [11]. These calculations, indicate that coreless AFPM machines with CNT windings may be used for applications where weight is critical, but the constraints on volume are not strict.

\section{CONCLUSION}

A multidisc coreless AFPM motor topology is proposed for a benchmark study on the suitability of current CNT wires for application in electric machine windings. The largest portion of mass for such a motor is due to copper coils. Aluminum coils and CNT material coils are used in place of copper coils to reduce the coil mass. These new materials have advantages over copper although their electrical conductivity is lower. Aluminum is lighter and less expensive, and CNT material, the most recent alternative, is much lighter, with no skin effect, and negligible temperature coefficient of resistance.

The derived main sizing equations indicate that lower electrical conductivity may be compensated by enlarging the dimensions of the machine. The results specify that the power per unit mass of this machine with non-conventional materials is higher than that of the copper based machine. For the same power output, the weight of the coreless AFPM machine designs with CNT and aluminum coils is $66 \%$ of that of the machine with copper coils.

Calculations based on three-dimensional FEA show that at higher speeds the improvement in power density achieved by using CNT is even more substantial. These calculations indicate that even with small improvements of the electrical conductivity, in line with short term expectations from materials engineering, the CNT version of the AFPM machine maybe already competitive for applications in which specific power per weight is important and volume is not a constraint.

\section{ACKNOWLEDGMENTS}

The support of University of Kentucky, the L. Stanley Pigman endowment, of ANSYS, Inc. and the expert advice of Dr. Ping Zhou are gratefully acknowledged.

\section{REFERENCES}

[1] A. Lekawa-Raus, J. Patmore, L. Kurzepa, J. Bulmer, and K. Koziol, "Electrical properties of carbon nanotube based fibers and their future use in electrical wiring," Advanced Functional Materials, vol. 24, no. 24, pp. 3661-3682, 2014.

[2] V. Rallabandi, N. Taran, D. M. Ionel, and J. F. Eastham, "On the feasibility of carbon nanotube windings for electrical machines: Case study for a coreless axial flux motor," IEEE Energy Conversion Congress and Exposition (ECCE), 2016.

[3] P. Juha, M. Juho, L. Pia, V. Julia, and O. Marcin, "At the cusp of the next electric motor revolution: Replacing copper with carbon nanomaterials," in International Conference on Energy Efficiency in Motor Driven Systems, 2015.

[4] L. Kurzepa, A. Lekawa-Raus, J. Patmore, and K. Koziol, "Replacing copper wires with carbon nanotube wires in electrical transformers," Advanced Functional Materials, vol. 24, pp. 619-624, 2014.

[5] R.-J. Wang and M. J. Kamper, "Calculation of eddy current loss in axial field permanent-magnet machine with coreless stator," IEEE Transactions on Energy Conversion, vol. 19, no. 3, pp. 532-538, Sept 2004.

[6] R. Hill-Cottingham, P. Coles, J. Eastham, F. Profumo, A. Tenconi, G. Gianolio, and M. Cerchio, "Plastic structure multi-disc axial flux pm motor," IEEE Industry Applications Conference, vol. 2, pp. 1274-1280, 2002.

[7] B. Yanniello, "Aluminum the other conductor," Eaton Electrical Inc., 2006.

[8] R. Hill-Cottingham, P. Coles, J. Eastham, F. Profumo, A. Tenconi, and G. Gianolio, "Multi-disc axial flux stratospheric aircraft propeller drive," IEEE Industry Applications Conference, vol. 3, pp. 1634-1639, 2001.

[9] A. Fatemi, D. M. Ionel, N. A. O. Demerdash, D. A. Statonz, R. Wrobelz, and Y. C. Chong, "A computationally efficient method for calculation of strand eddy current losses in electric machines," IEEE Energy Conversion Congress and Exposition (ECCE), 2016

[10] R. Wrobel, D. Salt, A. Griffo, N. Simpson, and P. Mellor, "Derivation and scaling of ac copper loss in thermal modeling of electrical machines," IEEE Transactions on Industrial Electronics, vol. 61, no. 8, pp. 4412-4420, 2014

[11] J. Widmer, C. Spargo, G. Atkinson, and B. Mecrow, "Solar plane propulsion motors with precompressed aluminum stator windings," IEEE Transactions on Energy Conversion, vol. 29, no. 3, pp. 681-688, 2014. 
Vandana Rallabandi (M'17) is a Post-doctoral Researcher in the SPARK Laboratory, Electrical and Computer Engineering Department, University of Kentucky, Lexington, KY. Prior to this, she was a Research Engineer at the General Electric (GE) Global Research Center in Bangalore, India She obtained the Masters and Ph.D. degrees at the Indian Institute of Technology Bombay, India. She has published over forty journal and conference proceedings papers, including three that received awards from IEEE, IET, and ICRERA, respectively, co-authored four book chapters, and has more than five invention disclosures and patent pending applications. She has been a reviewer for IEEE transactions on Industry Applications, Energy Conversion, Power Electronics, Industrial Electronics and Magnetics, IET Electric Power Applications and Electric Power Components and Systems. Her areas of work include electric machines, power electronics drives, renewable energy devices and systems, energy storage, and power systems.

Narges Taran (S'16) received her M.S. degree in Power Electronics and Electric Machines from K. N. Toosi University of Technology, Tehran, Iran, in 2014. In 2016, she started her PhD studies at University of Kentucky, Lexington, KY, were she is currently a PhD candidate. Her research focuses on electric machines, computational electromagnetics, optimization methodologies, and power electronic drives.

Dan M. Ionel (M'91-SM'01-F'13) received the M.Eng. and Ph.D. degrees in electrical engineering from the Polytechnic University of Bucharest, Bucharest, Romania. His doctoral program included a Leverhulme Visiting Fellowship at the University of Bath, Bath, U.K. He was a Post-Doctoral Researcher with the SPEED Laboratory, University of Glasgow, Glasgow, U.K.

$\mathrm{He}$ is currently Professor of Electrical Engineering and the L. Stanley Pigman Chair in Power with the University of Kentucky, Lexington, KY, where he also serves as the Director of the Power and Energy Institute of Kentucky (PEIK) and of the SPARK Laboratory. He previously worked in industry, most recently as a Chief Engineer with Regal Beloit, Corp., Grafton, WI, USA, and, before that, as the Chief Scientist for Vestas Wind Turbines. Concurrently, he also was a Visiting and Research Professor at the University of Wisconsin and Marquette University, Milwaukee, WI, USA. He contributed to technology developments with long lasting industrial impact, holds more than thirty patents, and published more than two hundred technical papers, including four that received IEEE awards.
Dr. Ionel was the inaugural Chair of the IEEE Industry Applications Society Renewable and Sustainable Energy Conversion Systems Committee and an Editor of the IEEE TRANSACTIONS ON SUSTAINABLE ENERGY. $\mathrm{He}$ is the Editor in-Chief of the Electric Power Components and Systems Journal, the Past Chair of the IEEE Power and Energy Society Electric Motor Subcommittee, and was the General Chair of the IEEE 2017 Anniversary Edition of the International Conference on Electrical Machines and Drives.

John F. Eastham graduated at Manchester University and was subsequently awarded Ph.D and D.Sc. degrees there. He was awarded a Doctorate Honoris Causa in 1998 by Bucharest University. After appointments at Manchester and Imperial College, he held a Chair of Engineering at Aberdeen University. He was appointed to a Chair and as Head of Department at Bath University in 1977. During his time at Bath he has held the positions of Dean and Pro-Vice-Chancellor. He is now an Emeritus Professor.

He was elected to a fellowship of the Royal Society of Edinburgh in 1975 and as a fellow of the Royal Academy of Engineering in 1986. Harbin University, China, appointed him Honorary Professor in 2007. He was a Royal Society Visiting Kan Tong Po Professor at Hong Kong University in 1998. He was awarded the Institution of Electrical Engineers Achievement Medal for Science, Education and Technology and the Powergen Partnership Award.

Professor Eastham was elected to a Fellowship of the Institution of Electrical Engineers in 1971 and has, in the past, served on a number of IEE committees including council. His public committee work has included chairmanship of the Science and Engineering Research Council Electrical Systems Committee. He served on the Royal Academy of Engineering International Committee, was a member of the Committee of Vice-Chancellors and Principals Awards Committee, a member of the Council for National Academic Awards and a Consultant to the Defence Scientific Advisory Council. He served as a main board director of the Mycalex Group Company. Professor Eastham's general field of interest is in machines and magnetics. He has some 160 published papers and 38 granted patents. He is currently active in the analysis and design of magnetic systems for MR imaging, wind turbine generators and large rotating and linear machines. 